\title{
The Biggest Threat Facing the Middle East Region
}

\begin{abstract}
Currently, the Middle East and North Africa (MENA) is a region filled with conflict and instability. Civil wars, religious sectarianism, and water scarcity are only a few of many threats facing the region. It is important to identify and prioritize these threats to be able to deal with them, starting from the most dangerous and so on. Unfortunately, this task is much harder in practice because of the lack of information or misinformation that is rampant in the region, and the strong desire of some to keep the status quo. The objective of this paper is to attempt to identify the biggest threat that faces the MENA region using the Analytic Hierarchy process (AHP). Information, including political and economic analysis of countries in the region, disaster reports, and general information and statistics about the region, is gathered to develop a hierarchal structure of the selection criteria and different threats as alternatives. The computer software Super Decisions is used to aid in the implementation of the AHP process. Finally, the biggest threat that is expected to have the greatest impact on the MENA region is identified.
\end{abstract}

Keywords: Analytic hierarchy process, AHP, threats, Middle East

\section{Introduction}

Nowadays, Middle East faces many threats with varying degrees of severity. It is necessary to determine the most dangerous in order to take the necessary actions to avoid or minimize its effect. Because this topic is usually skewed by opinions or by personal interests, the real threat might not be as obvious as it seems form watching the news. To choose the most dangerous threat, it is important to know the impact, urgency, solvability and magnitude of each threat. The biggest threat should have the highest impact, happen in the short term, be the hardest to solve and affect a large portion of the population. This report uses the Analytical Hierarchy Process to choose the biggest threat facing the Middle East, and it includes a literature review, hypotheses and objectives, research design/methodology, data/model analysis, limitation, and conclusion.

\section{Literature Review}

A research has been implemented in Mexico results that floods and droughts have major impact on poverty levels and human development [1]. According to Arlington Institute, the Earth's capacity to support human life will be severely strained as water crisis increases in coming decades [2]. On March 2011, the Syrian revolution began after the Syrian people have revolted on their president and the security forces opened fire on demonstrators, killing several, more took to the streets [3].

\section{Hypotheses/Objectives}

This paper attempts to determine the biggest threat faces the Middle East using an objective decision making process, the Analytic Hierarchy Process.

\section{Research Design/Methodology}

In this research, the goal, criteria, and alternatives are based on previous researches, literature reviews, academic advisors' opinions, and the authors' opinions. The strongest fact is that the authors live in the Middle East and this fact supports the research's results. While constructing the model, any inconsistency problem was solved by retrying the comparison.

\section{Data/Model Analysis}

The finalized analytical hierarchy is shown in the Fig. 1. 


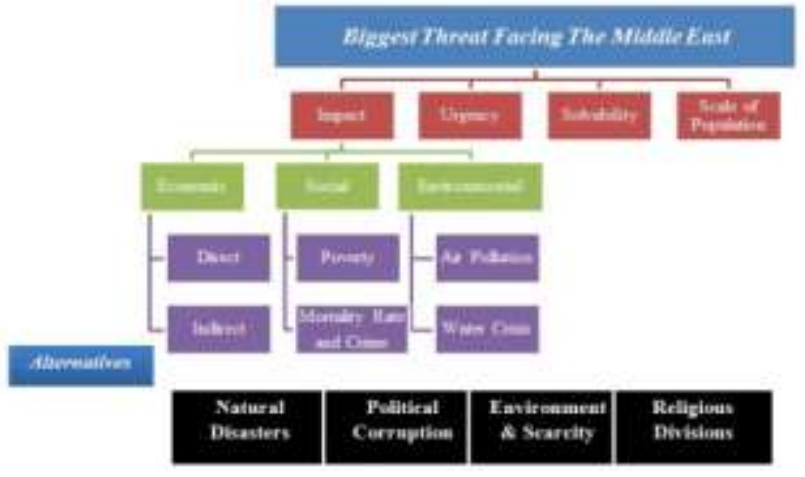

Figure 2: The analytical hierarchy diagram

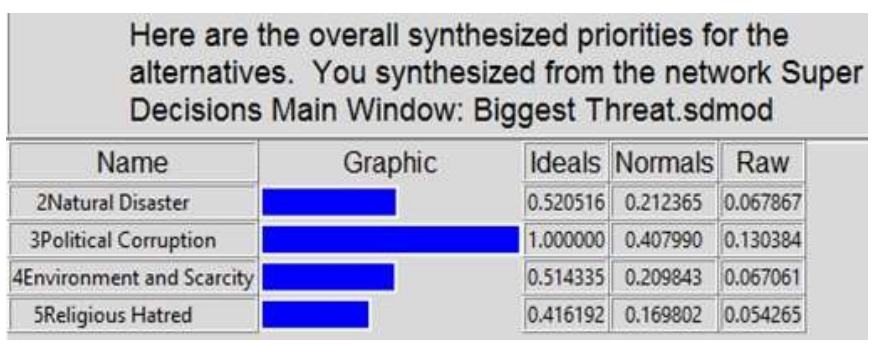

Figure 1: The Results

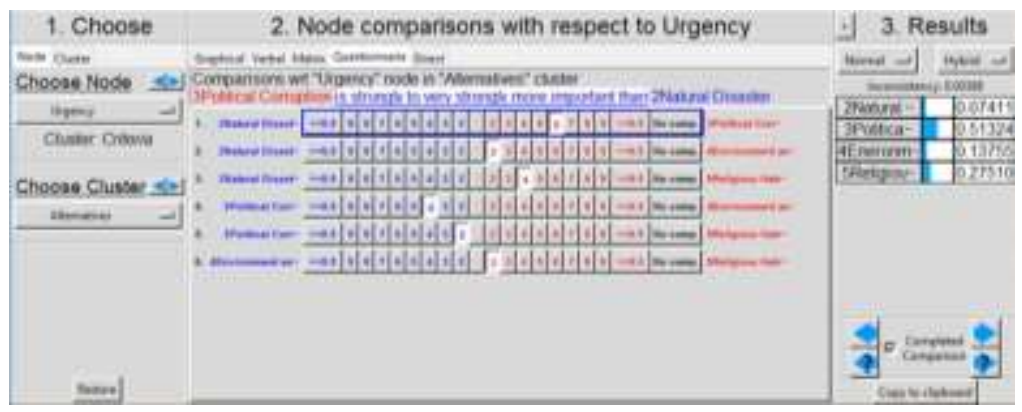

Figure 3: The analytical hierarchy diagram

\section{Limitations}

Trying to define the biggest threat in the Middle East is a very ambitious task to undertake, especially taking into account that students made this research, it is a pilot study, and it can be updated. The region is filled with complicated and intertwining factors that interact in unpredictable ways. The criteria and alternatives generated here were intended to be as comprehensive as possible. The information needed was hard to access and some were not available. With a little more time for research, the weights and priorities could probably be a more accurate representation of reality. In addition, more threats could be included and analyzed in the list of alternatives.

\section{Conclusions}

This paper discussed the case of choosing the Middle East biggest threat based on scientific methodology, which is the Analytical Hierarchy Process. This methodology allows the user to make pairwise comparisons upon different levels of the hierarchy in order to achieve the best decision of his case. This report included statistics, historical disasters analyses and opinions from different experts in order to complete the study.

\section{Key References}

[1] 2016.[Online].Available:http://www.preventionweb.net/english/hyogo/gar/backgroundpapers/documents/Chap3/LAC-overview/Mexico/Mexico.pdf. [Accessed: 13- Apr- 2016].

[2] "Global Water Crisis Overview | The Arlington Institute", Arlingtoninstitute.org, 2016. [Online]. Available: http://www.arlingtoninstitute.org/wbp/global-water-crisis/441. [Accessed: 13- Apr- 2016].

[3] BBC News, (2016). Syria: The story of the conflict - BBC News. [online] Available at: http://www.bbc.com/news/world-middle-east-26116868 [Accessed 20 Feb. 2016]. 